\title{
Proliferation of NG2-Positive Cells and Altered Oligodendrocyte Numbers in the Contused Rat Spinal Cord
}

\author{
Dana M. McTigue, Ping Wei, and Bradford T. Stokes \\ Department of Physiology and Cell Biology, The Ohio State University College of Medicine and Public Health, Columbus, \\ Ohio 43210
}

Given the numerous reparative roles glia may play after spinal cord injury (SCI), glial proliferation and cell number were examined in a model of traumatic SCl. Emphasis was placed on analysis of oligodendrocytes and NG2-positive (NG2+) cells, an endogenous cell population that may be involved in oligodendrocyte replacement. Overall, proliferation (assessed by bromodeoxyuridine incorporation) was markedly elevated during the first 2 weeks after injury and declined thereafter; a large portion of these dividing cells likely consisted of microgliamacrophages. Although the total number of NG2+ cells in the epicenter was reduced by half, we noted protracted proliferation in surviving NG2 + cells, with values sevenfold greater than in uninjured controls. Elevated proliferation of NG2 + cells persisted throughout the first 4 weeks after injury. However, the absolute number of NG2+ cells was not increased over controls, suggesting that the daughter cells either did not survive or

After spinal cord injury (SCI), tissue damage occurs at the impact site (i.e., epicenter) and spreads rostrally and caudally over time (for review, see Schwab and Bartholdi, 1996). This evolving lesion is characterized by prevalent oligodendrocyte apoptosis and loss of myelin around surviving axons (Gledhill et al., 1973; Harrison and McDonald, 1977; Balentine, 1978; Griffiths and McCulloch, 1983; Blight, 1985; Olby and Blakemore, 1996; Crowe et al., 1997). Demyelination of otherwise intact axons can lead to conduction failure and may contribute to the early functional deficits observed after spinal trauma. As seen in several animal models of SCI, axonal demyelination typically peaks during the first week after injury (Gledhill et al., 1973; Blight, 1985). Remyelination by oligodendrocytes and, depending on injury severity, infiltrating Schwann cells usually begins by $14 \mathrm{~d}$ after injury (Gledhill et al., 1973; Harrison and McDonald, 1977; Griffiths and McCulloch, 1983; McTigue et al., 2000). By 1 month after SCI, most axons have been remyelinated, although the new myelin sheaths are not as thick as those before injury (Blakemore, 1974; Gledhill and McDonald, 1977).

\footnotetext{
Received Jan. 2, 2001; revised Feb. 13, 2001; accepted Feb. 23, 2001.

This work was supported by the Christopher Reeve Paralysis Foundation and National Institutes of Health Grant NS 37321. We gratefully acknowledge Drs. Phillip Popovich and Lyn Jakeman for critical review of this manuscript and Zhen Guan and Patricia Walters for excellent technical support. The anti-BrdU antibody developed by S. J. Kaufman was obtained from the Developmental Studies Hybridoma Bank developed under the auspices of the National Institute of Child Health and Human Development and maintained by The University of Iowa, Department of Biological Sciences (Iowa City, IA).

Correspondence should be addressed to Dr. Dana M. McTigue, Department of Physiology and Cell Biology, 304 Hamilton Hall, 1645 Neil Avenue, Columbus, OH 43210. E-mail: mctigue.2@osu.edu.

Copyright (C) 2001 Society for Neuroscience $\quad 0270-6474 / 01 / 213392-09 \$ 15.00 / 0$
}

they differentiated into other cell types. As expected, oligodendrocyte numbers were drastically altered after SCI. By $7 \mathrm{~d}$ after injury, the number of oligodendrocytes at the impact site was reduced by $93 \%$. Despite ongoing tissue loss, the number of oligodendrocytes in spared tissue rose threefold at $14 \mathrm{~d}$ after injury. Although the function of NG2+ cells within the spinal cord is not completely understood, several studies suggest that they may differentiate into oligodendrocytes. Thus, proliferating $\mathrm{NG} 2+$ cells may contribute to the increased oligodendrocyte number observed at 2 weeks after injury. Future studies are required, however, to definitively determine the role NG2 + cells play in oligodendrocyte genesis, remyelination, and other postinjury events.

Key words: myelination; spinal cord injury; astrocyte; macrophage; microglia; progenitor cell; proliferation; oligodendrocyte

Work by Blakemore and Patterson (1978) has shown that remyelination can be prevented by inhibiting cell division with $\mathrm{x}$-irradiation, leading to the conclusion that mitosis is a prerequisite for CNS remyelination. Several studies, however, suggest that mature oligodendrocytes do not proliferate in response to demyelination or trauma (Keirstead and Blakemore, 1997; Amat et al., 1998; Carroll et al., 1998; Redwine and Armstrong, 1998). Thus, because proliferation is required for remyelination, it is unlikely that surviving oligodendrocytes contribute to this process after spinal cord trauma.

Interestingly, an oligodendrocyte progenitor cell population has been isolated from the adult CNS (ffrench-Constant and Raff, 1986; Wolswijk and Noble, 1989). These cells, which are as abundant as microglia and astrocytes (Chang et al., 2000), are found throughout the gray and white matter and can be visualized with antibodies against the platelet-derived growth factor- $\alpha$ (PDGF) receptor or the chondroitin sulfate proteoglycan NG2 (Stallcup and Beasley, 1987; Levine et al., 1993; Reynolds and Hardy, 1997; Nishiyama et al., 1999). Several lines of evidence suggest that these cells may contribute to remyelination. For instance, under appropriate in vitro conditions, oligodendrocyte progenitor cells from the adult CNS divide and differentiate into mature oligodendrocytes (ffrench-Constant and Raff, 1986; Wolswijk and Noble, 1989). Recently, it was shown that chemical demyelination of the spinal cord induced rapid proliferation of endogenous NG2-positive $(\mathrm{NG} 2+)$ cells before remyelination of the lesions (Carroll et al., 1998; Keirstead et al., 1998; Levine and Reynolds, 1999). If these spinal cords were x-irradiated, neither NG2 cell proliferation nor remyelination occurred, suggesting that the NG2+ cells were involved in the remyelination process 
(Keirstead et al., 1998). Furthermore, after transplantation into demyelinated spinal cords, oligodendrocyte progenitors differentiate into oligodendrocytes, which then successfully myelinate the bare axons (Groves et al., 1993; Franklin et al., 1995). Thus, these cells are responsive to CNS injury and play a role in remyelination.

In addition to replacing oligodendrocytes, a recent study suggests that, under appropriate culture conditions, oligodendrocyte progenitors isolated from the optic nerve also may give rise to neurons (Kondo and Raff, 2000). These results suggest that, in some instances, these progenitors may function as stem cells. Given the large numbers of these cells within the intact spinal cord, it will be important to determine how they are affected by SCI.

In the present study, we used bromodeoxyuridine (BrdU) to characterize the time course and distribution of cell division in the contused rat spinal cord at the impact site (epicenter) and in rostral and caudal regions of the lesion. Then, an antibody against NG2 was used to determine whether the dividing cell population included the NG2+ progenitors. To characterize other proliferating cells in the injured spinal cords, immunohistochemistry for BrdU was combined with markers for microglia-macrophages and astrocytes. In addition, temporal changes in oligodendrocyte number at the lesion epicenter were determined.

\section{MATERIALS AND METHODS}

Spinal cord injury. Adult female Fischer F344 rats (170-180 gm) were anesthetized with ketamine $(80 \mathrm{mg} / \mathrm{kg}$, i.p.) and xylazine $(10 \mathrm{mg} / \mathrm{kg}$, i.p. $)$ and given prophylactic antibiotic (Baytril, $1 \mathrm{mg} / \mathrm{kg}$ ). Under aseptic conditions, a dorsal laminectomy was performed at the T8 vertebral process to expose the spinal cord. Animals were stabilized in a spinal frame by clamping the spinous processes of the $\mathrm{T} 7$ and $\mathrm{T} 9$ vertebral bodies, and a contusion injury was produced using the Ohio State electromagnetic spinal cord injury device (Bresnahan et al., 1987; Stokes et al., 1992). Briefly, the computer-controlled impact probe was lowered onto the dorsal surface of the exposed spinal cord and used to rapidly displace the spinal tissue $1.1 \mathrm{~mm}$. Muscles overlying the spinal cord were sutured, and the skin was closed with wound clips and covered with antibiotic spray. The animals were hydrated with $5 \mathrm{cc}$ of Ringer's solution and were allowed to recover in warmed cages. Manual bladder expression was required for $10-14 \mathrm{~d}$ after injury. Animals were killed at $7(n=4), 14$ $(n=5), 28(n=4), 70(n=4)$, or $140(n=6) \mathrm{d}$ after injury. Four naïve animals served as noninjury controls.

The $1.1 \mathrm{~mm}$ displacement contusion results in a moderate to severe injury for these animals. Although they recover movement in all three joints of the hindlimb, the ability to consistently step is rarely achieved. This corresponds to a score of 10 on the Basso-Beattie-Bresnahan locomotor rating scale (Basso et al., 1995).

$\mathrm{BrdU}$ administration. Cellular proliferation was examined after SCI using the thymidine analog BrdU (50 mg/kg, i.p.; Boehringer Mannheim, Indianapolis, IN). Animals received a daily injection of BrdU for $7 \mathrm{~d}$ before being killed; thus, the proliferative response is discussed in terms of 1 week intervals.

Immunohistochemistry. Animals were deeply anesthetized with a ketamine-xylazine cocktail and exsanguinated by intracardiac perfusion with PBS, followed by $4 \%$ paraformaldehyde. Spinal cords were removed and post-fixed in $4 \%$ paraformaldehyde for $2 \mathrm{hr}$. The tissue was placed in $0.2 \mathrm{M}$ phosphate buffer overnight, followed by immersion in $30 \%$ sucrose overnight. Spinal cords were frozen on dry ice and cut into $2 \mathrm{~mm}$ blocks centered on the injury site. Tissue blocks were embedded in OCT compound (VWR Scientific Products, Bridgeport, NJ), cut on a cryostat at $10 \mu \mathrm{m}$, and mounted onto slides (ColorFrost/Plus; Fisher, Pittsburgh, PA).

For BrdU immunohistochemistry, $6 \%$ hydrogen peroxide was used to quench endogenous peroxidase activity, followed by PBS rinses and incubation in $1 \mathrm{~N} \mathrm{HCl}$ at $37^{\circ} \mathrm{C}$ for $30 \mathrm{~min}$. After rinsing, a blocking solution [4\% BSA in $0.1 \%$ Triton-100-PBS $\left(\mathrm{BP}^{+}\right)$] was applied for $1 \mathrm{hr}$; sections were subsequently incubated in mouse monoclonal anti-BrdU (1:200 in $\mathrm{BP}^{+}$; Developmental Studies Hybridoma Bank, University of Iowa, Iowa City, IA) at $4^{\circ} \mathrm{C}$ overnight in a humid chamber. The following day, sections were rinsed and incubated with biotinylated horse anti- mouse $\operatorname{IgG}$ secondary antibody $\left(1: 400\right.$ in $\left.\mathrm{BP}^{+}\right)$. Tissue was processed using Elite ABC (Vector Laboratories, Burlingame, CA) for $1 \mathrm{hr}$, followed by DAB substrate (Vector Laboratories) for $10 \mathrm{~min}$. Sections were dehydrated and coverslipped.

For double-labeling with NG2-BrdU or GFAP-BrdU, sections were processed for BrdU as above and then rinsed extensively in PBS. Sections were blocked with a serum-PBS solution and incubated with polyclonal NG2 antibody (1:1000; generous gift from Dr. William Stallcup, La Jolla Cancer Research Center, La Jolla, CA) or monoclonal GFAP antibody (1:8000; Sigma, St. Louis, MO) at $4^{\circ} \mathrm{C}$ overnight. Visualization was achieved by incubating with biotinylated goat anti-rabbit (1:400) or horse anti-mouse $\operatorname{IgG}(1: 400)$, respectively. Tissue was processed using Elite ABC (1 hr; Vector Laboratories) and SG substrate for 10 min (Vector Laboratories). For double-labeling of BrdU and mouse anti-OX42 (1: 2000 in PBS; Harlan Sprague Dawley, Indianapolis, IN), the above protocol was modified such that OX42 immunohistochemistry preceded that for BrdU.

To visualize mature oligodendrocyte cell bodies, the $\mathrm{CC} 1$ antibody (also called APC; Oncogene Research Products, Cambridge, MA) was used. This antibody clearly labels oligodendrocyte somas without labeling myelin sheaths, which greatly facilitates cell counting. However, some labeling of Schwann cells and astrocytes was noted; thus, a protocol was developed to combine $\mathrm{CC} 1$ immunohistochemistry with that for P0 to label Schwann cell myelin (generous gift from Dr. Juan Archelos, Universitatsklinik für Neurologie, Graz, Austria) and GFAP to identify astrocytes. Sections were preincubated in $\mathrm{BP}^{+}$followed by incubation in mouse monoclonal $\mathrm{CC} 1\left(1: 500\right.$ in $\left.\mathrm{BP}^{+}\right)$at $4^{\circ} \mathrm{C}$ overnight. Secondary antibody (1:400) was applied for $2 \mathrm{hr}$ at room temperature, after which tissue was rinsed and incubated in $6 \%$ hydrogen peroxide. Tissue was processed with Elite $\mathrm{ABC}$ and $\mathrm{DAB}$ substrate for $15 \mathrm{~min}$. After thorough rinsing, the above protocol was repeated for P0 immunohistochemistry using the VIP substrate followed by GFAP immunohistochemistry using the SG substrate. Sections were counterstained with methyl green. A CC1+ cell was counted as an oligodendrocyte if it demonstrated round to oval morphology, little cytoplasm, and no immunoreactivity for P0 or GFAP.

Quantitation. Tissue was analyzed using a Zeiss (Thornwood, NY) Axioplan microscope with a Sony (Tokyo, Japan) 970 three-chip color camera. For quantification, two sections from the epicenter spaced $\sim 100$ $\mu \mathrm{m}$ apart were analyzed for each animal and then averaged. To examine proliferation occurring within the lesion extensions, cells also were quantified in sections $2 \mathrm{~mm}$ rostral and caudal to the impact site at which the structural integrity of the spinal cord was compromised as early as $7 \mathrm{~d}$ after injury, albeit much less so than at the epicenter. Cellular proliferation was determined by counting the total number of BrdU+ nuclei in spinal cord cross-sections. Sections were digitized at low power and manually outlined using an image analysis system (MCID; Imaging Research Inc., St. Catharines, Ontario, Canada); any cavities present in the sections were excluded from analysis. Positively labeled nuclei were counted automatically. The threshold was set such that only positively labeled profiles of the appropriate size were counted. Data are expressed as cells per section.

The total number of $\mathrm{NG} 2+$ cells and the number of those that proliferated was determined by manually counting at high power $(640 \times)$ all NG2+ cells within the cross-sections and then, on nearby sections, counting all cells double-labeled for NG2 and BrdU. Because NG2 becomes deposited extracellularly in the spinal injured tissue (our unpublished observation), cell counting was done conservatively, and an $\mathrm{NG} 2+$ profile was only counted as a cell if clearly defined borders could be detected completely around and adjacent to the entire nucleus. Because sections were only $10-\mu \mathrm{m}$-thick and NG2 + cell bodies are $\sim 10$ $\mu \mathrm{m}$, it is likely that BrdU+ nuclei belonged to the NG2+ cells in those cells counted as double-labeled. In addition, focusing through the section enabled the verification that BrdU+ nuclei and NG2 + cell bodies were in focus in the same plane of section. Data are expressed as cells per section.

The number of mature oligodendrocytes in the tissue sections was determined by manually counting single-labeled $\mathrm{CC} 1+$ oligodendrocytes. This antibody does not label myelin profiles, allowing clear delineation of oligodendrocyte somas. All oligodendrocytes in each crosssection were manually counted at high power $(640 \times)$, and the sections were digitized and manually outlined to determine cross-sectional area. Data are expressed as cells per section.

For all analyses, control (i.e., naïve) values from spinal cord sections at T8 (site of impact in injured spinal cords) were not significantly different from those in sections $2 \mathrm{~mm}$ rostral and caudal; thus, these data were 


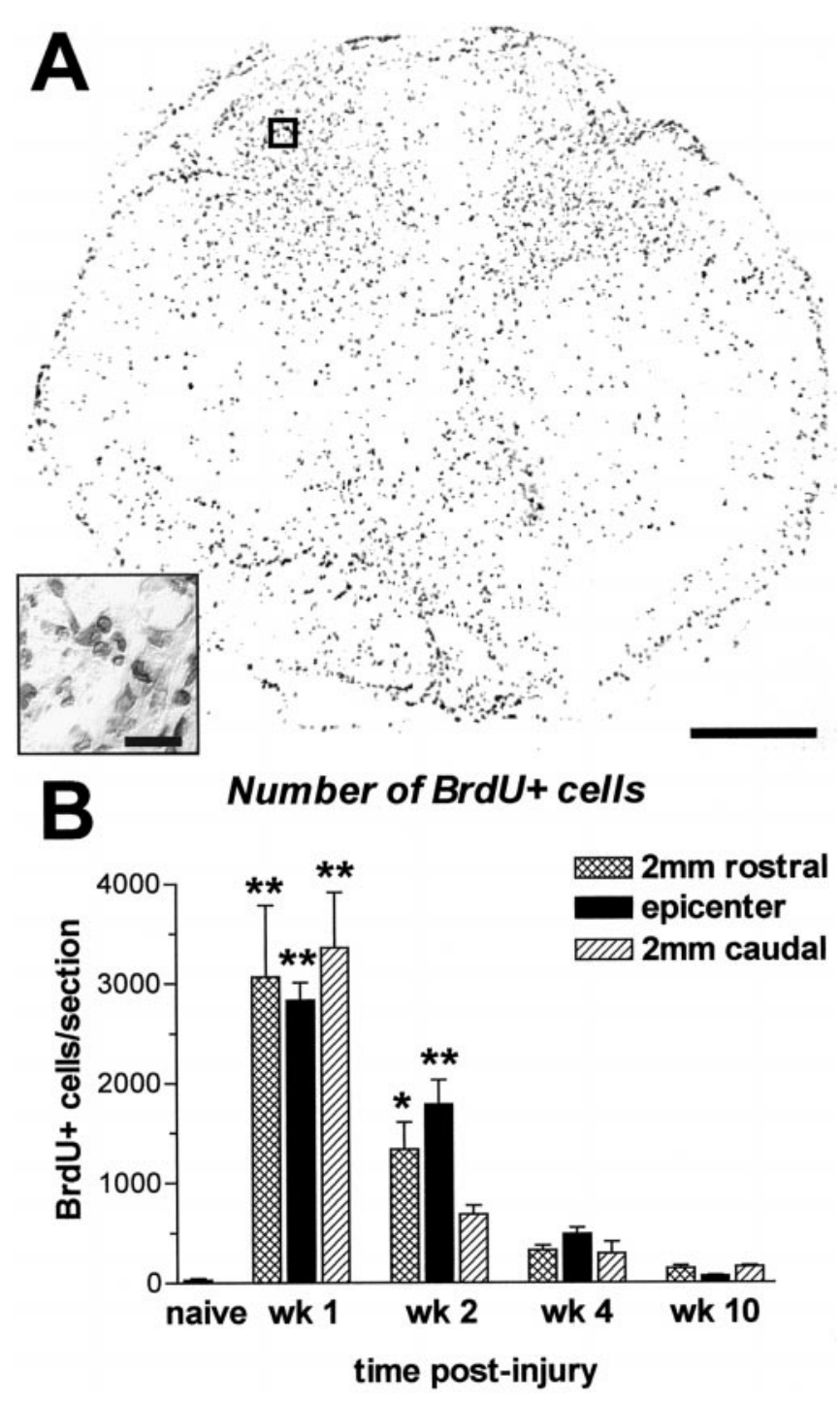

Figure 1. Distribution and time course of cell proliferation after spinal cord contusion injury. $A$, Epicenter section from $7 \mathrm{~d}$ post-injury spinal cord labeled immunohistochemically for BrdU. Note that most BrdU+ cells are found within the former dorsal horns and the central region of the cross-section. Scale bar, $0.4 \mathrm{~mm}$. Inset, High-power view of the box in $A$. Several nuclei positively labeled for BrdU are visible. Scale bar, $20 \mu \mathrm{m}$. $B$, Quantification of total number of BrdU+ nuclei in cross-sections from the impact site and rostral and caudal regions of the lesion. Noninjured (naive) spinal cords contained minimal BrdU + cells (30 cells per section). The number of dividing cells was significantly increased during the first and second weeks after injury at the epicenter. Proliferation also was elevated in rostral and caudal sections during the first week and in rostral sections during the second week after injury. Error bars represent means \pm SEM. ${ }^{*} p<0.05 ;{ }^{*} p<0.01$.

collapsed into one control value for each analysis. Control values were compared with the experimental groups using a one-way ANOVA, followed by a Dunnett's multiple comparison test. Significance was set at $p<0.05$.

\section{RESULTS}

\section{Cellular proliferation after spinal cord injury}

The number of proliferating cells was determined by counting all BrdU + nuclei in epicenter cross-sections at different times after injury. In cross-sections from the impact site at $7 \mathrm{~d}$ after injury, most BrdU+ cells labeled during the first week were located centrally or in the region of the former dorsal horns (Fig. 1A).
During this first week after injury, cell division rose 100 -fold to $>2800$ BrdU + cells per section and was significantly greater compared with naïve spinal cords in which $\sim 30 \mathrm{BrdU}+$ cells were detected $(p<0.01)$ (Fig. 1B). Proliferation in the epicenter remained elevated during the second week after injury $(\sim 1800$ cells per section) and declined thereafter.

Increased numbers of BrdU+ nuclei also were found over the first week after injury in rostral and caudal regions of the lesion in which $>3000 \mathrm{BrdU}+$ cells per section were counted $(p<0.01)$ (Fig. $1 B$ ). At this time, most dividing cells were concentrated in the region of the gray matter and the dorsal funiculus. Although cell division declined in caudal sections after the first week, it remained significantly elevated in rostral sections during the second week after injury $(p<0.05)$. In fact, BrdU+ cell numbers in rostral sections were twice those in caudal sections during this time. By the fourth week after injury, proliferation in the rostral sections was approaching control levels.

\section{NG2 expression on progenitors, macrophages, and Schwann cells in the injured spinal cord}

An antibody against the NG2 chondroitin sulfate was used to identify progenitor cells typically thought to belong to the oligodendrocyte lineage. These cells are normally found throughout the spinal gray and white matter (for an example, see Fig. $2 A, B$ ). Double-labeling the sections with NG2 and BrdU immunohistochemistry allowed detection and counting of proliferating progenitors (Fig. 2C). After SCI, NG2 immunoreactivity increased throughout the lesion site (Fig. 2D). NG2 labeling in the injured spinal cord was not restricted to the progenitor cell population, however, but also included a subset of macrophages and infiltrating Schwann cells. These cells could be distinguished from the progenitor cells morphologically. For instance, NG2 labeling on macrophages consisted of a thin rim of immunopositivity near the cell membrane at some distance from the nucleus (Fig. 2E,F). Such profiles were not included in the cell counts. NG2-labeled macrophages were occasionally observed in $7 \mathrm{~d}$ post-injury tissue and were more common in 14 and $28 \mathrm{~d}$ post-injury sections. They were rare in more chronic tissue.

Schwann cells have been shown to infiltrate the spinal cord after injury and myelinate axons therein. In the present study, a thin rim of NG2 was often noted around the peripheral edge of Schwann cells and their accompanying myelin profiles within the injured spinal cord (data not shown). However, because of their characteristic round morphology, these cells could be differentiated from the typical multipolar or bipolar morphology of the progenitor cells (Fig. 2C).

\section{NG2 progenitors proliferate in response to spinal cord injury}

Progenitor proliferation was determined by manually counting all cells double-labeled with NG2 and BrdU antibodies in spinal cord cross-sections (Fig. $2 C$ ). In naïve animals, minimal turnover in the $\mathrm{NG} 2+$ cell population was detected (approximately six cells per section) (Fig. 3A); this is consistent with the work of others showing limited turnover in these cells in normal adult rat spinal cord (Horner et al., 2000). During the first week after SCI, the number of BrdU+/NG2+ cells within the epicenter tripled; these cells were detected throughout the epicenter cross-sections, in spared as well as lesioned tissue. At this time in rostral and caudal lesion extensions, double-labeled cells were over sixfold higher than controls (38-40 cells per section; $p<0.01$ ) (Fig. $3 A$ ). By the second week after injury, double-labeled cells in the epicenter 


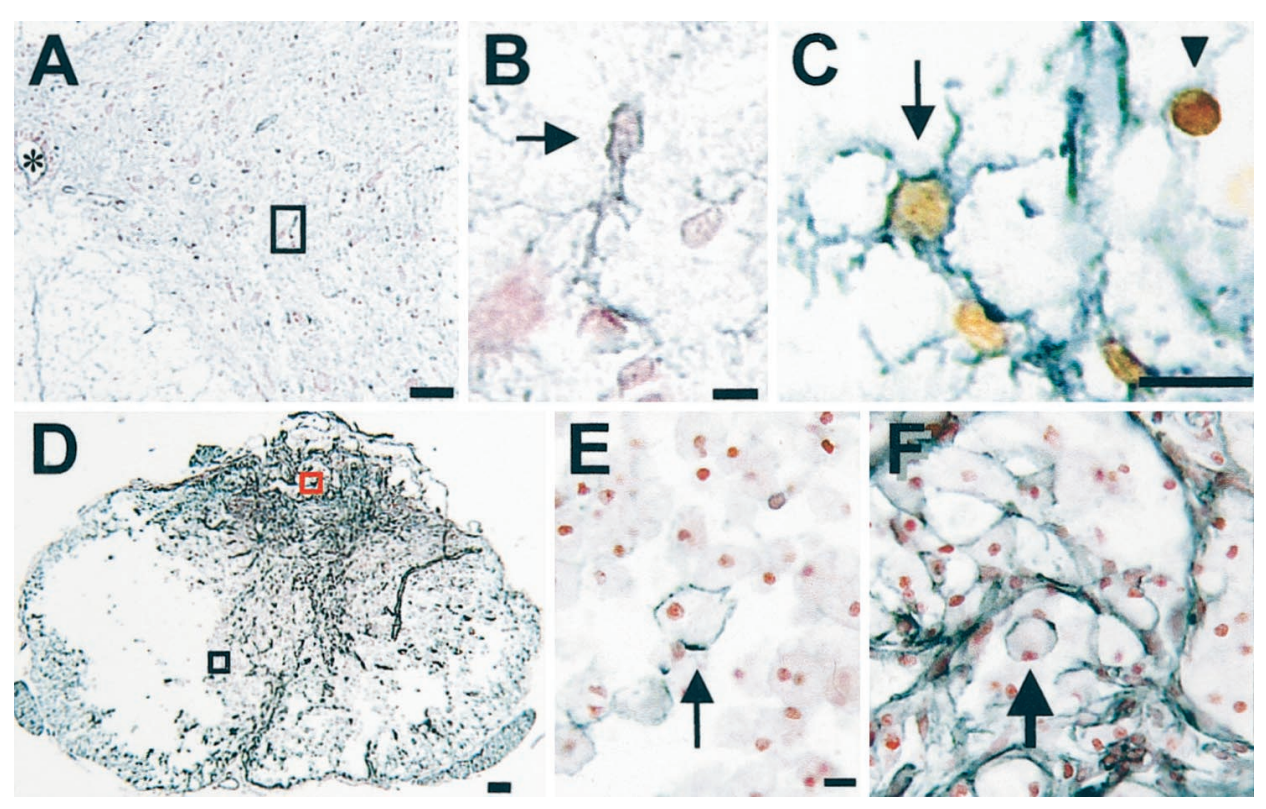

Figure 2. NG2 labels progenitor cells and a subset of macrophages in the injured spinal cord. $A$, Example of NG2 immunostaining in a normal spinal cord (counterstained with neutral red). NG2+ progenitor cells are evenly distributed throughout the gray and white matter. The central canal is denoted with an asterisk. Scale bar, $50 \mu \mathrm{m}$. $B$, High-power view of the box from gray matter in $A$ illustrating cell soma and processes positively labeled for NG2 (arrow). Scale bar, $5 \mu \mathrm{m}$. $C$, Example of a cell (arrow) double-labeled for NG2 (gray) and BrdU (brown) from a section $2 \mathrm{~mm}$ rostral to the epicenter at $7 \mathrm{~d}$ after injury. A single-labeled BrdU + nucleus is indicated by the arrowhead. Scale bar, $10 \mu \mathrm{m}$. $D$, Low-power view of a $28 \mathrm{~d}$ post-injury epicenter cross-section immunolabeled for NG2 and counterstained with neutral red. Increased NG2 immunoreactivity is present within the dorsal funiculus, central region, and spared white matter. Scale bar, $100 \mu \mathrm{m}$. E, High-power view of field within the black box in D. A macrophage located within the lesion cavity with NG2 immunoreactivity present on the cell membrane is denoted with an arrow. Several nonlabeled macrophages are also visible. Scale bar: $E, F, 10 \mu \mathrm{m}$. $F$, High-power view of field within the red box in $D$ taken from the dorsal funiculus. An NG2+ macrophage (arrow) is visible within a region of increased NG2 deposition.

were 3.8-fold greater, reaching levels of 23 cells per cross-section $(p<0.05)$. NG2 + cell proliferation remained elevated in rostral and caudal lesion extensions in which a 4.5 -fold increase to 26 and 28 double-labeled cells per section was detected, respectively $(p<0.05)$ (Fig. 3A). By the fourth week after injury, NG2+ cell proliferation had declined in rostral and epicenter sections, but remained elevated caudally (29 cells per section; $p<0.01$ ).

Counting the number of $\mathrm{BrdU}+/ \mathrm{NG} 2+$ cells provides information on the absolute number of dividing progenitor cells in injured spinal cord sections. However, because the lesion evolves and expands with time, these cell counts do not reflect the proportion of NG2 cells that are dividing. Thus, the total number of NG2 + cells was determined and used to calculate the percentage of the remaining NG2 cell population labeled with BrdU (expressed as a labeling index). In normal thoracic spinal cord cross-sections, the number of NG2+ cells was $\sim 140$ (Fig. $3 B$ ). At $7 \mathrm{~d}$ after injury, this number had decreased $55 \%$ to $64 \mathrm{NG} 2+$ cells per section $(p<0.05)$ (Fig. $3 B)$, indicating that over half of the endogenous NG2+ cells were lost early after SCI. By the second post-injury week, the number of NG2+ cells had risen within the epicenter to 106 cells per section and remained stable over time. At 10 weeks after injury, the number of $\mathrm{NG} 2+$ cells in rostral and caudal sections declined to 67 and 98 cells per section, respectively ( $p<0.05$ for rostral sections) (Fig. 3B).

The labeling index of NG2 cells was calculated by dividing the number of BrdU+/NG2+ cells by the total number of NG2+ cells for each animal. Because BrdU was given only once per day, this labeling index is an approximate because some dividing cells may not have incorporated BrdU. During the first week after injury, the percentage of $\mathrm{NG} 2+$ cells dividing in the epicenter $(30 \%)$ was significantly greater than that in controls $(4 \% ; p<$ 0.01 ) (Fig. $3 C$ ). Thus, although the total number of NG2+ cells had declined during the first $7 \mathrm{~d}$ after injury, the percentage of those cells dividing was greater than in normal spinal cords. The labeling index also was elevated in rostral and caudal sections during the first week ( $p<0.01$ and $p<0.05$, respectively) (Fig. $3 C)$. The proliferative response remained elevated within the epicenter for at least 4 weeks after injury and declined to basal levels by 10 weeks after injury.

\section{Proliferation of microglia, macrophages, and astrocytes after SCI}

The number of proliferating NG2 cells comprises only a small portion of the BrdU+ cells seen in Figure 1. Previous studies using tritiated thymidine have suggested that activated microglia, macrophages, and astrocytes proliferate after SCI (Adrian and Walker, 1962). Thus, additional staining was performed to label new microglia and macrophages (OX42/BrdU) and new astrocytes (GFAP/BrdU). Double-labeling with OX42 and BrdU revealed a general overlap in the areas labeled with BrdU and OX42 (Fig. 4A). Examination of these sections under high power revealed many $\mathrm{OX} 42+$ macrophages with BrdU + nuclei within the epicenter (Fig. 4B). Because of the overlapping nature of these cells, quantification of double-labeled cells was not possible. In the rostral and caudal spinal cord, upregulated microglial activation and proliferation could be detected for several millimeters in otherwise normal-appearing tissue; for instance, microglial proliferation was observed in sections $1 \mathrm{~cm}$ distal to the epicenter at $7 \mathrm{~d}$ after injury (Fig. $4 C, D$ ). Thus, the endogenous microglia several millimeters away from the impact site respond rapidly to the trauma, as indicated by altered morphology and increased proliferation.

GFAP immunohistochemistry revealed that most remaining astrocytes were located in the outer rim of spared tissue (Fig. $4 E$ ). Only occasional astrocytes with BrdU+ nuclei were detected (Fig. $4 F$ ), suggesting that astrocyte proliferation occurs at a low level after spinal contusion injury.

\section{Oligodendrocyte cell number is decreased by $\mathrm{SCI}$}

It is thought that the NG2+ cells play a role in generating new oligodendrocytes after CNS injury. Based on the findings in Figure 3 showing increased NG2 cell proliferation after SCI, we examined how oligodendrocyte numbers were altered in the injured spinal cord. Oligodendrocytes were identified as round or 

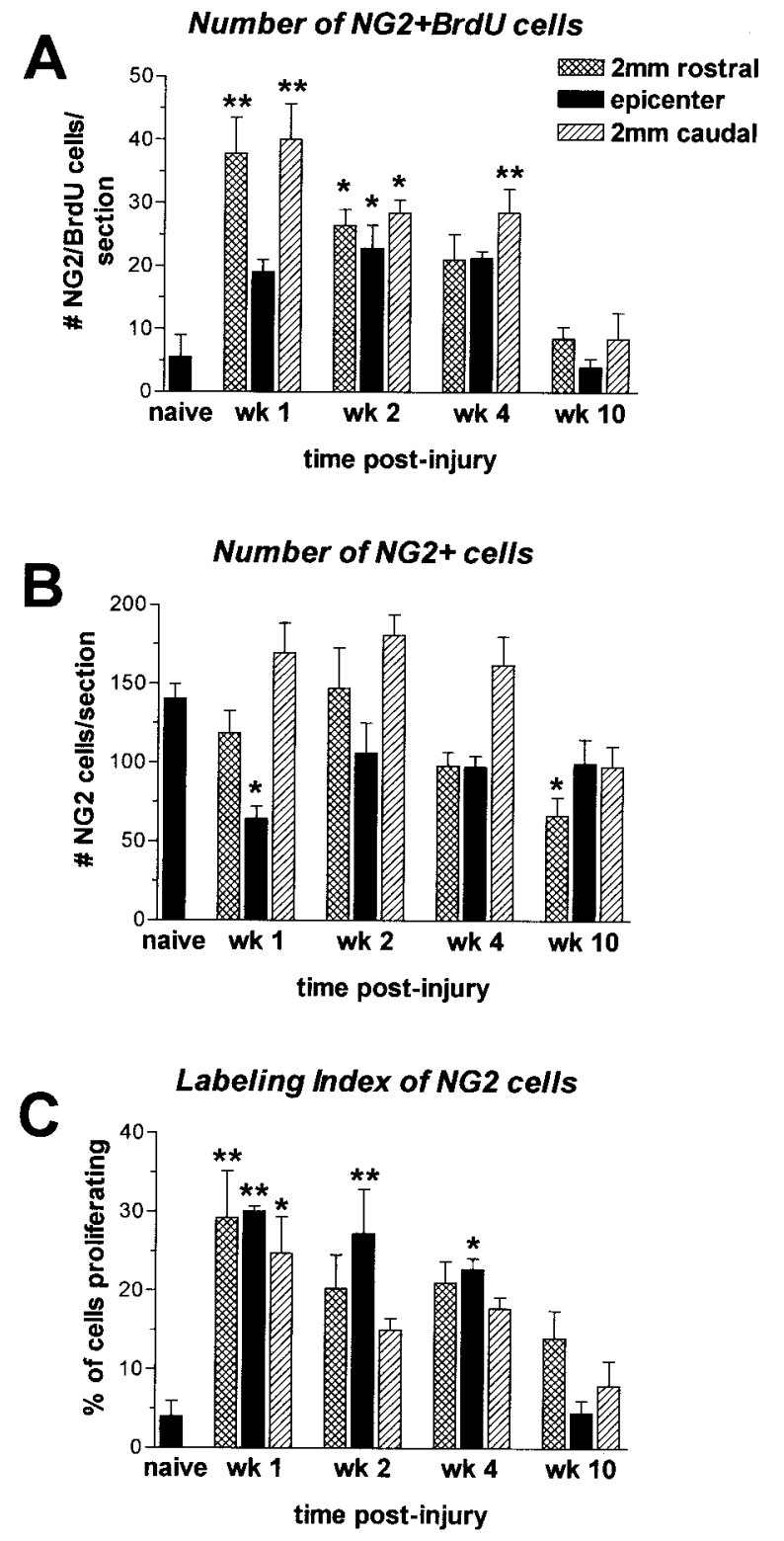

Figure 3. Quantification of NG2+ cells, NG2+/BrdU + cells, and labeling index of dividing NG2 + cells within the epicenter and rostral and caudal regions of the lesion. $A$, Cells double-labeled for NG2 and BrdU were manually counted in cross-sections from the epicenter and $2 \mathrm{~mm}$ rostral and caudal after spinal contusion injury. An average of six doublelabeled cells were detected in noninjured control tissue. After SCI, there was a significant increase in double-labeled cells during the first week after injury in rostral and caudal regions of the lesion, in all three regions during the second week, and in the caudal region during the fourth week after injury. $B$, All NG2+ cells in spinal cord cross-sections were manually counted. Approximately 140 cells per section were detected in spinal cord sections from normal animals. At $7 \mathrm{~d}$ after injury, NG2+ cell numbers were significantly reduced in the epicenter to 64 cells per section. This number increased to 106 cells per section at $14 \mathrm{~d}$ after injury and remained stable. At 10 weeks after injury, there were significantly fewer cells within sections $2 \mathrm{~mm}$ rostral to the impact site (67 cells per section). $C$, The labeling index of NG2 + cells was determined by dividing the number of cells doublelabeled for NG2 and BrdU by the total number of NG2 cells for each animal. In naïve animals, $\sim 4 \%$ of NG2 + cells were double-labeled with BrdU, indicating a low turnover normally in this cell population. During the first week after injury, proliferation of these cells was significantly elevated within the epicenter and rostral and caudal regions of the lesion. This proliferation remained elevated within the epicenter until at least 4 weeks after injury and returned to baseline levels by 10 weeks after injury. Error bars represent means \pm SEM. ${ }^{*} p<0.05 ;{ }^{* *} p<0.01$. oval single-labeled $\mathrm{CC} 1+$ cells showing no immunoreactivity or association with $\mathrm{P} 0+$ myelin and no immunoreactivity for GFAP (Fig. 5A-C).

At $7 \mathrm{~d}$ after injury, the number of oligodendrocytes present in epicenter cross-sections was reduced $93 \%$ to $\sim 86$ cells per section $(p<0.01)$ (Fig. 5D). Thus, most oligodendrocytes in the impact site were lost within the first week after injury. Interestingly, at $14 \mathrm{~d}$ after injury, the number of oligodendrocytes had risen threefold to reach $22 \%$ of normal levels (257 cells per section; $p<$ 0.01 vs control) (Fig. $5 D$ ). After that time, oligodendrocyte numbers decreased and remained at $\sim 13 \%$ of controls $(p<0.01)$. It should be noted that there was continual loss of spinal cord tissue for up to 5 months after injury (Fig. $5 E$ ). This perhaps accounts for chronic cavitation as continuous loss of axon, myelin, and/or cellular debris occurs. However, by 4 weeks after injury, oligodendrocyte numbers had stabilized, and they remained constant at later times.

\section{DISCUSSION}

\section{Cellular proliferation is stimulated in the injured spinal cord}

Using BrdU, we have demonstrated that proliferation is markedly increased in the epicenter of contused rat spinal cords over the first 2 weeks after injury. Cell division was highest during the first week after injury and declined to nonsignificant levels by 4 weeks. These data are in accordance with earlier studies using tritiated thymidine, which demonstrated increased cell division acutely after SCI (Adrian and Walker, 1962; Adrian, 1968). In the present study, many BrdU+ macrophages were observed within the epicenter, demonstrating that these cells comprised a large proportion of the dividing cells. Within the spared white matter, low-level astrocyte proliferation was noted, as has been seen previously after SCI (Adrian and Walker, 1962). Based on other studies, unidentified BrdU+ cells likely also include ependymal cells, endothelial cells, and fibroblasts (Adrian and Walker, 1962; Adrian et al., 1978; Namiki and Tator, 1999).

Increased cell division was not limited to the impact site but also occurred in the lesion extensions. Indeed, at $7 \mathrm{~d}$ after injury, the number of BrdU+ cells in sections $2 \mathrm{~mm}$ rostral and caudal equaled that in the lesion epicenter. Interestingly, microglial proliferation was prevalent in sections up to $1 \mathrm{~cm}$ distal from the epicenter, suggesting that microglia throughout the spinal cord are particularly sensitive to localized traumatic events. During the second week after injury, BrdU+ cell numbers decreased caudally but remained elevated in rostral sections. The reason for different cellular responses in these regions is not clear; however, previous studies have emphasized other rostral-caudal differences. For instance, Popovich et al. (1996) detected more extensive vascular permeability rostral to spinal contusion injuries than in caudal regions.

\section{Possible roles for proliferating NG2+ progenitors after $\mathbf{S C I}$}

Remyelination requires cell division (Blakemore and Patterson, 1978). Because most in vivo studies suggest that mature oligodendrocytes are postmitotic (Godfraind et al., 1989; Keirstead and Blakemore, 1997; Amat et al., 1998; Carroll et al., 1998; Redwine and Armstrong, 1998), proliferation of a less differentiated cell type likely accounts for remyelination after spinal trauma. Interestingly, Wrathall et al. (1998) demonstrated upregulated myelin transcription factor 1 after spinal contusion, suggesting an increased presence of oligodendrocyte progenitors. PDGF $\alpha$ 


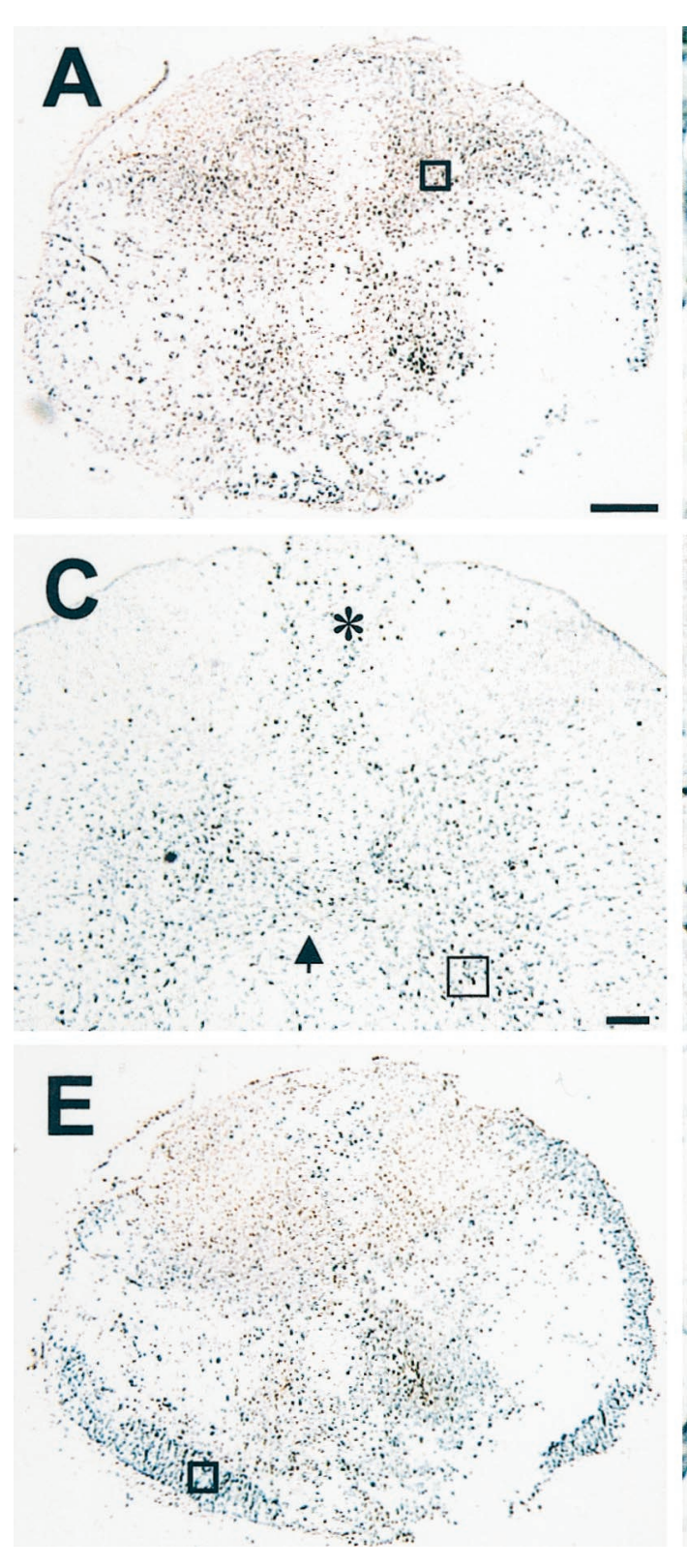

Figure 4. Proliferating cells in the injured spinal cord include microglia, macrophages, and astrocytes. Double-label immunohistochemistry for OX42 (microglia and macrophages; gray) and $\operatorname{BrdU}$ (brown; $A-D)$, and GFAP (astrocytes; gray) and BrdU (brown; $E, F) . A$, Epicenter cross-section at $7 \mathrm{~d}$ after injury. Most BrdU + cells and OX42+ cells are located in the central region of the section in an overlapping manner. $B$, Highpower view of the box in $A$. Several macrophages double-labeled with OX42 and BrdU are visible (arrows). Arrowheads indicate two macrophages without BrdU+ nuclei. Scale bar: $B, F, 10 \mu \mathrm{m}$. $C$, Section $1 \mathrm{~cm}$ rostral to epicenter at $7 \mathrm{~d}$ after injury. Many activated microglia were visible, especially within the fasciculus gracilis (asterisk) and gray matter. Central canal is indicated by the arrow. Scale bar, $100 \mu \mathrm{m}$. $D$, High-power view of the box in $C$ showing a ramified microglial cell double-labeled with BrdU, indicating that microglial cells relatively long distances from the impact site respond rapidly to SCI. Scale bar, $5 \mu \mathrm{m}$. E, Epicenter cross-section at $7 \mathrm{~d}$ after injury. Most GFAP+ cells are located within the spared rim of tissue, whereas most $\mathrm{BrdU}+$ cells are found centrally. $F$, Highpower view of the box in $E$. One astrocyte double-labeled with GFAP ( gray) and BrdU (brown) is denoted by the arrow. receptor-positive oligodendrocyte progenitors have been shown to coexpress NG2 in vivo (Nishiyama et al., 1996). Because in vitro work has shown that NG2+ cells can differentiate into oligodendrocytes (Stallcup and Beasley, 1987), we examined whether the $\mathrm{NG} 2+$ cell population was included in the pool of cells dividing in the injured spinal cord. Indeed, NG2+ cell proliferation was significantly upregulated during the first week after injury and maintained at least through the next 3 weeks, which is a surprising finding given that proliferation in general had declined by this time.

This time course of NG2+ cell proliferation parallels the time of demyelination and remyelination. Several studies examining the status of myelination after SCI demonstrated demyelination over the first $7 \mathrm{~d}$ after injury, followed by a period of remyelination that was mostly complete within 2-4 weeks (Gledhill et al., 1973; Harrison and McDonald, 1977; Griffiths and McCulloch, 1983; Blight, 1985). Interestingly, NG2+ cells are known to proliferate in response to demyelination (Carroll et al., 1998; Keirstead et al., 1998). Thus, it is possible that surviving NG2+ cells were induced to divide early after injury by denuded axons within the injury site in an effort to increase the pool of oligodendrocytes available for remyelination. However, factors present within the injured spinal cord responsible for stimulating NG2+ cell proliferation at this and later times, i.e., 2-4 weeks after injury, remain to be definitively determined. Nevertheless, this timing of $\mathrm{NG} 2+$ cell proliferation suggests a possible role for these cells in remyelinating the injured spinal cord.

Although we did not determine whether NG2 cells differentiated into mature oligodendrocytes, studies using markers specific to different stages of the oligodendrocyte lineage suggest that these oligodendrocyte progenitors can differentiate in vivo (Warrington and Pfeiffer, 1992; Reynolds and Hardy, 1997). Furthermore, when prelabeled progenitor cells were transplanted into demyelinated lesions in the spinal cord, they were able to divide, migrate, and differentiate into myelinating oligodendrocytes (Groves et al., 1993; Franklin et al., 1995). This, along with in vitro studies demonstrating that NG2+ oligodendrocyte progenitors can differentiate into mature oli- 
Figure 5. Oligodendrocyte numbers are drastically reduced early but are maintained chronically in the injured spinal cord. $A-C$, Examples of triple-label immunohistochemistry for CC1 (brown), GFAP (black), and P0 (purple) used to count oligodendrocytes. Sections are from lesion epicenter at $28 \mathrm{~d}$ after injury and are counterstained with methyl green. Scale bars, $5 \mu \mathrm{m}$. $A$, Several single-labeled oligodendrocytes (brown; arrowheads) and one astrocyte (black; arrow) are visible. Image taken from lateral white matter. $B$, Example of GFAP+ astrocyte double-labeled with CC1. Image from dorsolateral edge of white matter. $C$, Image taken from lateral white matter in a region in which several Schwann cells with $\mathrm{P} 0+$ myelin were visible. In this field, two Schwann cells were clearly double-labeled with $\mathrm{CC} 1$ and P0 (arrows), whereas one Schwann cell was single-labeled for P0 (arrowhead). D, Quantification of oligodendrocytes singlelabeled with $\mathrm{CC} 1$ in epicenter crosssections. At $7 \mathrm{~d}$ after injury, oligodendrocytes were significantly reduced by $93 \%$ compared with sections taken from normal spinal cords at T8 (which contained $1165 \pm 113$ oligodendrocytes). The number of oligodendrocytes remained significantly lower than controls as late as 5 months after injury. However, between 7 and $14 \mathrm{~d}$ after injury, oligodendrocyte numbers increased more than threefold. E, Quantification of cross-sectional area of epicenter sections at different times after injury. Digitized sections
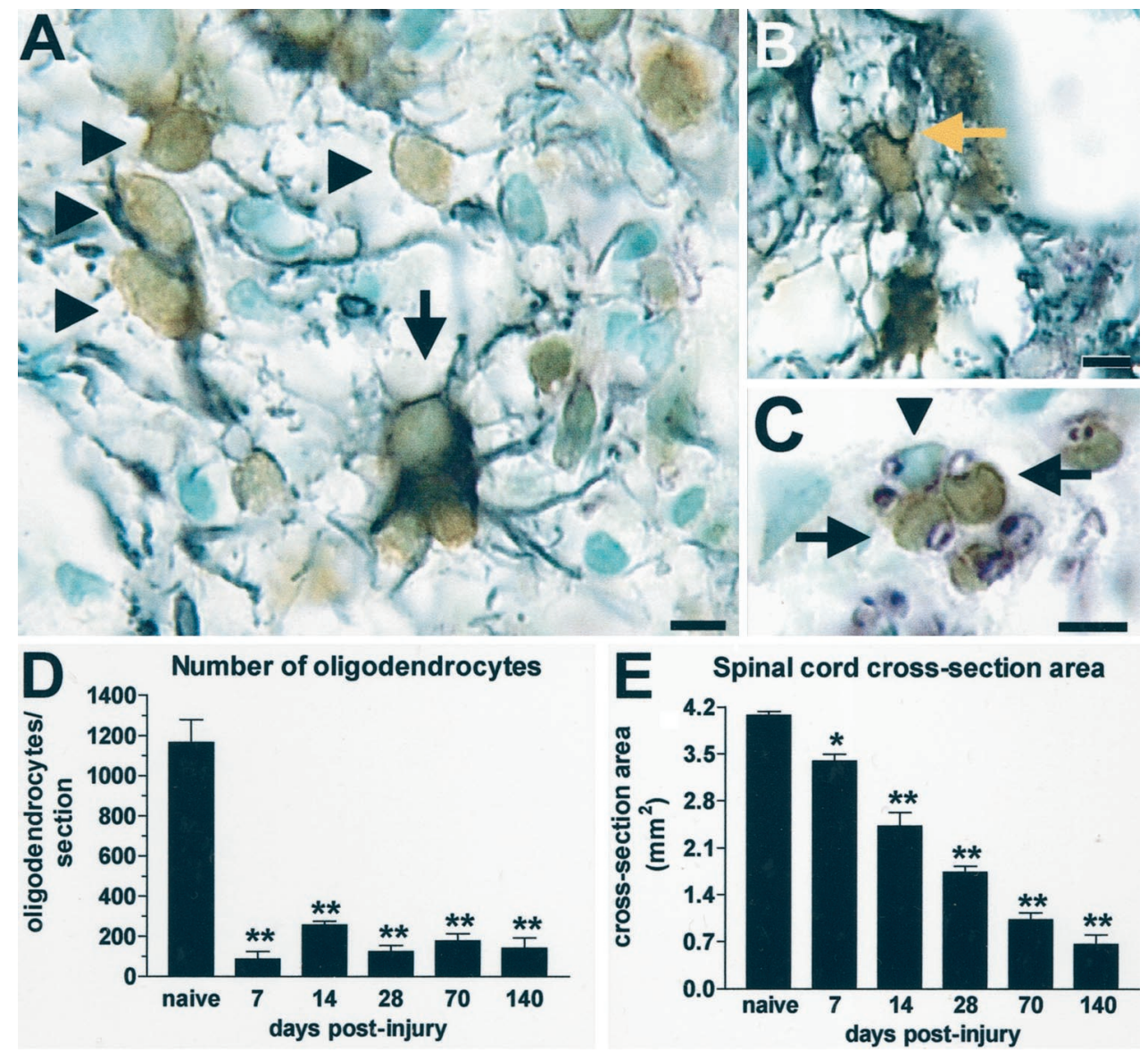
were manually outlined and cavities were excluded such that only the remaining tissue area was measured. A continual loss of spinal cord tissue for at least 5 months after injury was detected.

godendrocytes (Stallcup and Beasley, 1987; Nishiyama et al., 1999), suggests that such cells may be important in replacing oligodendrocytes lost after CNS trauma.

It should be noted, however, that $\mathrm{NG} 2+$ cells may have additional functions in the CNS. Recent in vivo work has revealed that cells of this lineage can receive direct synaptic contacts, send processes to nodes of Ranvier and into synaptic clefts, and intermingle with activated microglia (Nishiyama et al., 1997; Butt et al., 1999; Ong and Levine, 1999; Bergles et al., 2000). Furthermore, a recent study demonstrated that isolated oligodendrocyte progenitor cells can be induced to generate neurons in addition to oligodendrocytes and astrocytes and therefore may be a type of stem cell (Kondo and Raff, 2000). Thus, NG2+ cells may play important roles in the normal as well as pathological CNS, which include but are not limited to oligodendrocyte replacement.

Accordingly, Keirstead et al. (1998) have suggested that NG2 cells within the CNS are a heterogeneous population. In their study, cells induced to proliferate in response to spinal cord demyelination were killed by $\mathrm{x}$-irradiation. The results revealed an $\sim 50 \%$ reduction in the number of $\mathrm{NG} 2$ cells in the $\mathrm{x}$-irradiated region, suggesting that only half of the NG2 cells in the vicinity of the demyelinated lesion underwent mitosis. Using a model of spinal contusion injury and daily BrdU injections, we have determined that $\sim 30 \%$ of the surviving NG2 cells were induced to proliferate. The role of nonproliferating NG2 cells in the intact and injured CNS remains to be determined.

\section{Oligodendrocytes are lost early after SCI at the epicenter}

Previous work has shown that, after SCI, oligodendrocyte numbers in the surviving ventral funiculus are not significantly altered (Frei et al., 2000). However, oligodendrocyte apoptosis occurs throughout the injured spinal cord (Li et al., 1996; Crowe et al., 1997; Liu et al., 1997), and the issue of replacement of dying oligodendrocytes remains. Thus, we counted the total number of oligodendrocytes present in cross-sections from injured spinal cords at several times after injury. Within the epicenter, $93 \%$ of the oligodendrocytes were lost by $7 \mathrm{~d}$. At this time, significant tissue necrosis and massive macrophage accumulation are obvious with this model of SCI (Popovich et al., 1997). Interestingly, a recent paper examining oligodendrocyte loss in multiple sclerosis plaques revealed that decreased oligodendrocyte cell number was highly correlated with increased numbers of macrophages (Lucchinetti et al., 1999). In addition, several reports have demonstrated that macrophages can be toxic to oligodendrocytes (Matyszak and Perry, 1995; Matyszak et al., 1997; O’Leary et al., 1998). Because macrophage accumulation was significant by $7 \mathrm{~d}$ after injury, it is possible that these cells, or a subset thereof, were involved in oligodendrocyte loss. In a recent report by Popovich et al. (1999), clodronate liposomes were used to deplete peripheral monocytes acutely after rat SCI. In these animals, white matter sparing was significantly increased, suggesting that peripherally derived macrophages are deleterious to surviving oligoden- 
drocytes and may be a contributing factor to the loss of these cells early after SCI.

At $14 \mathrm{~d}$ after injury, the average number of oligodendrocytes within epicenter cross-sections was 257 , a threefold increase from the previous week. The mechanism for this increase is not known, but it is possible that they were derived from $\mathrm{NG} 2+$ progenitor cells that proliferated during the first week after injury. Approximately 20 NG2 cells with BrdU nuclei were detected in epicenter sections at $7 \mathrm{~d}$ after injury. Assuming that most of the dividing NG2 cells were labeled, three doublings of this population would have to occur between 7 and $14 \mathrm{~d}$ after injury to account for the threefold increase in oligodendrocytes. Previous in vitro work has revealed that adult oligodendrocyte progenitors have a cycle time of $65 \mathrm{hr}$ and require $>5 \mathrm{~d}$ to differentiate into mature oligodendrocytes (Wolswijk and Noble, 1989). Therefore, if NG2+ cell proliferation and differentiation accounted for the rise oligodendrocytes during the second week after injury, the rate of proliferation and differentiation may have been accelerated by the injured spinal cord environment and/or there may have been incomplete labeling of all proliferating cells with the currently used protocol of one BrdU injection per day.

Between 14 and 28 d after injury, the number of oligodendrocytes was reduced $\sim 50 \%$. Because remyelination is thought to be mostly complete by $28 \mathrm{~d}$, it is possible that extra oligodendrocytes generated at 2 weeks after injury did not encounter bare axons and were eliminated, similar to what occurs developmentally. This reduction in oligodendrocytes occurred, although elevated $\mathrm{NG} 2+$ cell proliferation was maintained during this time. This further suggests that the role of NG2+ cells in the injured CNS may not be exclusively limited to oligodendrocyte genesis. This is especially intriguing given that, during this time of elevated NG2 cell proliferation, the total number of NG2 + cells did not change; the fate of these dividing cells is currently unknown. At later times, i.e., 28-140 d after injury, the number of oligodendrocytes remained steady, even as the cross-sectional area of the epicenter decreased because of ongoing tissue cavitation. This maintenance of oligodendrocytes may be attributable to a halt in their death and/or continued differentiation and replacement by progenitor cells.

\section{Conclusions}

Proliferation of NG2+ progenitors can be added to the growing list of endogenous repair processes initiated in the injured spinal cord. The present data suggest that a window of several weeks exists after SCI in which the endogenous NG2+ cells proliferate. Given the putative stem cell activity and potential remyelinative roles of these cells, a greater understanding of their functions and fate in the injured CNS is imperative.

\section{REFERENCES}

Adrian Jr EK (1968) Cell division in injured spinal cord. Am J Anat 123:501-520.

Adrian Jr EK, Walker BE (1962) Incorporation of thymidine- $\mathrm{H}^{3}$ by cells in normal and injured mouse spinal cord. J Neuropathol Exp Neurol 21:597-609.

Adrian Jr EK, Williams MG, George FC (1978) Fine structure of reactive cells in injured nervous tissue labeled with $3 \mathrm{H}$-thymidine injected before injury. J Comp Neurol 180:815-839.

Amat JA, Farooq M, Ishiguro H, Norton WT (1998) Cells of the oligodendrocyte lineage proliferate following cortical stab wounds: an in vitro analysis. Glia 22:64-71.

Balentine JD (1978) Pathology of experimental spinal cord trauma. II. Ultrastructure of axons and myelin. Lab Invest 39:254-266.

Basso DM, Beattie MS, Bresnahan JC (1995) A sensitive and reliable locomotor rating scale for open field testing in rats. J Neurotrauma 12:1-21.

Bergles DE, Roberts JD, Somogyi P, Jahr CE (2000) Glutamatergic synapses on oligodendrocyte precursor cells in the hippocampus. Nature 405:187-191.

Blakemore WF (1974) Pattern of remyelination in the CNS. Nature 249:577-578.

Blakemore WF, Patterson RC (1978) Suppression of remyelination in the CNS by X-irradiation. Acta Neuropathol (Berl) 42:105-113.

Blight AR (1985) Delayed demyelination and macrophage invasion: a candidate for secondary cell damage in spinal cord injury. Cent Nerv Syst Trauma 2:299-315.

Bresnahan JC, Beattie MS, Todd III FD, Noyes DH (1987) A behavioral and anatomical analysis of spinal cord injury produced by a feedbackcontrolled impaction device. Exp Neurol 95:548-570.

Butt AM, Duncan A, Hornby MF, Kirvell SL, Hunter A, Levine JM, Berry M (1999) Cells expressing the NG2 antigen contact nodes of Ranvier in adult CNS white matter. Glia 26:84-91.

Carroll WM, Jennings AR, Ironside LJ (1998) Identification of the adult resting progenitor cell by autoradiographic tracking of oligodendrocyte precursors in experimental CNS demyelination. Brain 121:293-302.

Chang A, Nishiyama A, Peterson J, Prineas J, Trapp BD (2000) NG2Positive oligodendrocyte progenitor cells in adult human brain and multiple sclerosis lesions. J Neurosci 20:6404-6412.

Crowe MJ, Bresnahan JC, Shuman SL, Masters JN, Beattie MS (1997) Apoptosis and delayed degeneration after spinal cord injury in rats and monkeys. Nat Med 3:73-76.

ffrench-Constant C, Raff MC (1986) Proliferating bipotential glial progenitor cells in adult rat optic nerve. Nature 319:499-502.

Franklin RJ, Bayley SA, Milner R, ffrench-Constant C, Blakemore WF (1995) Differentiation of the O-2A progenitor cell line CG-4 into oligodendrocytes and astrocytes following transplantation into gliadeficient areas of CNS white matter. Glia 13:39-44.

Frei E, Klusman I, Schnell L, Schwab ME (2000) Reactions of oligodendrocytes to spinal cord injury: cell survival and myelin repair. Exp Neurol 163:373-380.

Gledhill RF, McDonald WI (1977) Morphological characteristics of central demyelination and remyelination: a single-fiber study. Ann Neurol $1: 552-560$.

Gledhill RF, Harrison BM, McDonald WI (1973) Demyelination and remyelination after acute spinal cord compression. Exp Neurol 38:472-487.

Godfraind C, Friedrich VL, Holmes KV, Dubois-Dalcq M (1989) In vivo analysis of glial cell phenotypes during a viral demyelinating disease in mice. J Cell Biol 109:2405-2416.

Griffiths IR, McCulloch MC (1983) Nerve fibres in spinal cord impact injuries. I. Changes in the myelin sheath during the initial 5 weeks. J Neurol Sci 58:335-349.

Groves AK, Barnett SC, Franklin RJ, Crang AJ, Mayer M, Blakemore WF, Noble M (1993) Repair of demyelinated lesions by transplantation of purified O-2A progenitor cells. Nature 362:453-455.

Harrison BM, McDonald WI (1977) Remyelination after transient experimental compression of the spinal cord. Ann Neurol 1:542-551.

Horner PJ, Power AE, Kempermann G, Kuhn HG, Palmer TD, Winkler J, Thal LJ, Gage FH (2000) Proliferation and differentiation of progenitor cells throughout the intact adult rat spinal cord. J Neurosci 20:2218-2228.

Keirstead HS, Blakemore WF (1997) Identification of post-mitotic oligodendrocytes incapable of remyelination within the demyelinated adult spinal cord. J Neuropathol Exp Neurol 56:1191-1201.

Keirstead HS, Levine JM, Blakemore WF (1998) Response of the oligodendrocyte progenitor cell population (defined by NG2 labelling) to demyelination of the adult spinal cord. Glia 22:161-170.

Kondo T, Raff M (2000) Oligodendrocyte precursor cells reprogrammed to become multipotential CNS stem cells. Science 289:1754-1757.

Levine JM, Reynolds R (1999) Activation and proliferation of endogenous oligodendrocyte precursor cells during ethidium bromide-induced demyelination. Exp Neurol 160:333-347.

Levine JM, Stincone F, Lee YS (1993) Development and differentiation of glial precursor cells in the rat cerebellum. Glia 7:307-321.

Li GL, Brodin G, Farooque M, Funa K, Holtz A, Wang WL, Olsson Y (1996) Apoptosis and expression of Bcl-2 after compression trauma to rat spinal cord. J Neuropathol Exp Neurol 55:280-289.

Liu XZ, Xu XM, Hu R, Du C, Zhang SX, McDonald JW, Dong HX, Wu YJ, Fan GS, Jacquin MF, Hsu CY, Choi DW (1997) Neuronal and glial apoptosis after traumatic spinal cord injury. J Neurosci 17:5395-5406.

Lucchinetti C, Bruck W, Parisi J, Scheithauer B, Rodriguez M, Lassmann H (1999) A quantitative analysis of oligodendrocytes in multiple sclerosis lesions. A study of 113 cases. Brain 122:2279-2295.

Matyszak MK, Perry VH (1995) Demyelination in the central nervous system following a delayed-type hypersensitivity response to bacillus Calmette-Guerin. Neuroscience 64:967-977.

Matyszak MK, Townsend MJ, Perry VH (1997) Ultrastructural studies of an immune-mediated inflammatory response in the CNS parenchyma directed against a non-CNS antigen. Neuroscience 78:549-560.

McTigue DM, Wei P, Stokes BT (2000) Oligodendrocyte progenitor 
proliferation and Schwann cell invasion in the injured rat spinal cord. J Neurotrauma 16:1013.

Namiki J, Tator CH (1999) Cell proliferation and nestin expression in the ependyma of the adult rat spinal cord after injury. J Neuropathol Exp Neurol 58:489-498.

Nishiyama A, Lin XH, Giese N, Heldin CH, Stallcup WB (1996) Colocalization of NG2 proteoglycan and PDGF $\alpha$-receptor on O2A progenitor cells in the developing rat brain. J Neurosci Res 43:299-314.

Nishiyama A, Yu M, Drazba JA, Tuohy VK (1997) Normal and reactive $\mathrm{NG} 2+$ glial cells are distinct from resting and activated microglia. J Neurosci Res 48:299-312.

Nishiyama A, Chang A, Trapp BD (1999) NG2+ glial cells: a novel glial cell population in the adult brain. J Neuropathol Exp Neurol 58:1113-1124.

O'Leary MT, Bujdoso R, Blakemore WF (1998) Rejection of wild-type and genetically engineered major histocompatibility complex-deficient glial cell xenografts in the central nervous system results in bystander demyelination and Wallerian degeneration. Neuroscience 85:269-280.

Olby NJ, Blakemore WF (1996) Primary demyelination and regeneration of ascending axons in the dorsal funiculus of the rat spinal cord following photochemically induced injury. J Neurocytol 25:465-480.

Ong WY, Levine JM (1999) A light and electron microscopic study of NG2 chondroitin sulfate proteoglycan-positive oligodendrocyte precursor cells in the normal and kainate-lesioned rat hippocampus. Neuroscience 92:83-95.

Popovich PG, Horner PJ, Mullin BB, Stokes BT (1996) A quantitative spatial analysis of the blood-spinal cord barrier. I. Permeability changes after experimental spinal contusion injury. Exp Neurol 142:258-275.
Popovich PG, Wei P, Stokes BT (1997) Cellular inflammatory response after spinal cord injury in Sprague-Dawley and Lewis rats. J Comp Neurol 377:443-464.

Popovich PG, Guan Z, Wei P, Huitinga I, van Rooijen N, Stokes BT (1999) Depletion of hematogenous macrophages promotes partial hindlimb recovery and neuroanatomical repair after experimental spinal cord injury. Exp Neurol 158:351-365.

Redwine JM, Armstrong RC (1998) In vivo proliferation of oligodendrocyte progenitors expressing PDGF $\alpha \mathrm{R}$ during early remyelination. J Neurobiol 37:413-428.

Reynolds R, Hardy R (1997) Oligodendroglial progenitors labeled with the $\mathrm{O} 4$ antibody persist in the adult rat cerebral cortex in vivo. J Neurosci Res 47:455-470.

Schwab ME, Bartholdi D (1996) Degeneration and regeneration of axons in the lesioned spinal cord. Physiol Rev 76:319-370.

Stallcup WB, Beasley L (1987) Bipotential glial precursor cells of the optic nerve express the NG2 proteoglycan. J Neurosci 7:2737-2744.

Stokes BT, Noyes DH, Behrmann DL (1992) An electromechanical spinal injury technique with dynamic sensitivity. J Neurotrauma 9:187-195.

Warrington AE, Pfeiffer SE (1992) Proliferation and differentiation of $\mathrm{O} 4+$ oligodendrocytes in postnatal rat cerebellum: analysis in unfixed tissue slices using anti-glycolipid antibodies. J Neurosci Res 33:338-353.

Wolswijk G, Noble M (1989) Identification of an adult-specific glial progenitor cell. Development 105:387-400.

Wrathall JR, Li W, Hudson LD (1998) Myelin gene expression after experimental contusive spinal cord injury. J Neurosci 18:8780-8793. 